\title{
Sistem Kendali Jarak Jauh dan Monitoring Penggunaan Listrik pada Pompa Air Melalui Smartphone
}

\author{
Ratna Aisuwarya, Ahmad Fauzi \\ Jurusan Sistem Komputer,FTI Universitas AndalasLimau Manis Kec. Pauh, Kota Padang, Sumatera Barat 25163 INDONESIA
}

\section{ARTICLE INFORMATION}

Received: February $8^{\text {th }}, 2020$

Revised: March $9^{\text {th }}, 2020$

Available online: March $30^{\text {th }}, 2020$

\section{KEYWORDS}

control system, water pump, monitoring, electricity usage

\section{CORRESPONDENCE}

Phone: +62 8112014117

E-mail: aisuwarya.unand@gmail.com

\section{A B S T R A C T}

This study aims to create a control system that can turn on / turn off the water pump by simply pressing a button on the smartphone and monitoring how much electricity was used which will later be converted into cost value in rupiahs. This system is able to further regulate the use of water pumps, such as restrictions on daily use, restrictions on use at certain hours, and pumps can be set to automatically shut down after a few moments of use. This system consists of three main components, namely an embedded system, a website-based mobile application, and a web server. The embedded system consists of Wemos D1, ACS712 current sensor, and relay. From the tests conducted the system can turn on the water pump with an average response time of 2 seconds and the results of monitoring conducted have an average error value of $13.63 \%$ as a result of current sensors.

\section{PENDAHULUAN}

Perkembangan teknologi membantu manusia memenuhi kebutuhannya menjadi lebih mudah dan cepat. Salah satunya yaitu pada bidang sistem kendali. Sistem kendali atau sistem kontrol (control system) adalah suatu alat atau kumpulan alat dalam satu kesatuan yang saling terhubung untuk mengendalikan, memerintah, dan mengatur keadaan dari suatu sistem[1]. Selama ini, sistem kendali jarak jauh dapat dilakukan dengan menggunakan remote control berbasis infrared atau saklar yang terhubung melalui rangkaian kabel. Akan tetapi, sistem kendali tersebut dibatasi oleh jarak operasi yang pendek dan penjangkauan yang susah, sehingga masih kurang efektif.

Salah satu peralatan rumah tangga yang kurang efektif dalam sistem kendalinya adalah pompa air yang umumnya masih menggunakan colokan listrik atau saklar. Dalam beberapa kasus, satu pompa air bisa jadi digunakan oleh dua atau lebih keluarga berbeda, contohnya dengan tetangga dekat ataupun tetangga yang jaraknya cukup jauh. Di sini terdapat dua permasalahan, yaitu dari sisi pengguna pompa air harus pergi terlebih dahulu ke tempat keluarga yang memiliki pompa air agar dapat menghidupkannya, dan dari sisi pemilik pompa air tidak dapat memantau berapa penggunaan pompa air oleh tiap-tiap keluarga, atau secara lebih umum permasalahannya terletak pada sistem kendali dan monitoring pompa air tersebut.

Untuk itu, agar dapat menyelesaikan permasalahan yang terjadi pada kos tersebut, diperlukan sebuah sistem yang dapat mengendalikan sekaligus memonitor penggunaan daya listrik pada pompa air. Smartphone, dapat digunakan sebagai remote control sekaligus sebagai alat untuk memonitor penggunaan daya listrik pompa air. Selanjutnya yaitu wifi digunakan sebagai media komunikasi antar smartphone dengan sistem tertanam yang dibuat. Smartphone yang selalu dibawa dan dimiliki oleh kebanyakan orang saat ini serta wifi yang memiliki kelebihan dalam hal jarak menjadikan alasan penulis menggunakannya.

Pada penelitian sebelumnya telah membahas perancangan sistem kendali penerangan dengan melakukan berbagai simulasi[2]. Pada penelitian lainnya telah membahas tentang sistem monitoring beban listrik yang kemudian dikonversi ke dalam nilai rupiah[3]. Dua penelitian ini masing-masing hanya memiliki satu fungsi yaitu sistem kendali saja dan sistem monitoring saja. Penelitian ini bertujuan untuk menggabungkan dua fungsi sekaligus, yaitu untuk sistem kendali dan monitoring. Sistem kendali yang digunakan sudah menggunakan media komunikasi wifi sehingga dapat digunakan di manapun selama terkoneksi internet. Tak hanya untuk menghidupkan dan mematikan saja, sistem ini juga mampu mengendalikan secara lebih mendalam seperti, pembatasan pemakaian berdasarkan tingkat pengguna, pembatasan pemakaian pada jam-jam tertentu, pembatasan pemakaian jika telah mencapai batas harian, dan sistem otomatis mati setelah beberapa saat. Dari segi monitoring, sistem juga dapat lebih spesifik menentukan lama pemakaian dari masing-masing pengguna pompa air. 


\section{LANDASAN TEORI}

\section{Sistem Kendali}

Sistem kendali atau sistem kontrol mempunyai pengertian sebagai suatu sistem yang dapat mengendalikan, mengatur, memerintahkan dan mengontrol sebuah alat untuk melakukan sesuatu. Secara teori sistem kontrol merupakan susunan dari beberapa komponen yang disusun sedemikian rupa sehingga mampu dan bisa mengatur sistemnya sendiri atau sistem di luarnya. Sistem kontrol ini mempunyai hubungan timbal balik antara komponennya sehingga membentuk konfigurasi sistem yang memberikan suatu hasil yang dikehendaki berupa respon[1].

\section{Sistem Monitoring}

Sistem monitoring merupakan suatu proses untuk mengumpulkan data dari berbagai sumber daya. Biasanya data yang dikumpulkan merupakan data yang real time. Sistem monitoring adalah suatu sistem yang bisa digunakan untuk mengamati suatu data dari alat ukur oleh manusia dimanapun tempat dan kapanpun waktunya[4].

\section{Pompa Air}

Pompa Air adalah suatu rangkaian elektronika yang dikemas menjadi suatu instrumen, yang mempunyai fungsi sebagai penyedia aliran air dalam debit besar dengan prinsip kerja menghisap air yang tersedia dan mendistribusikan aliran air tersebut kepada setiap saluran keluaran air. Untuk pembagian jenis dari rangkaian pompa air dapat diklasifikasikan melalui kekuatan daya hisap, daya listrik yang dikonsumsi, level ketinggian distribusi air, dan level ketinggian penampungan air. Perhitungan dari daya hisap air dan daya listrik yang dikonsumsi biasanya akan sebanding, jadi apabila pompa air mengalirkan air dalam jumlah debit yang besar maka akan semakin besar pula daya yang dikonsumsi oleh rangkaian pompa air[5].

Stator merupakan bagian yang diam sebagai rangka tempat kumparan stator yang terpasang. Stator terdiri dari : inti stator, kumparan stator, dan alur stator yang bisa dilihat pada Gambar 1. Motor induksi satu phasa dilengkapi dengan dua kumparan stator yang dipasang terpisah, yaitu kumparan utama (main winding) atau sering disebut dengan kumparan berputar dan kumparan bantu (auxiliary winding) atau sering disebut dengan kumparan start. Rotor merupakan bagian yang berputar. Pada bagian ini terdiri dari inti rotor kumparan rotor dan alur rotor [6].

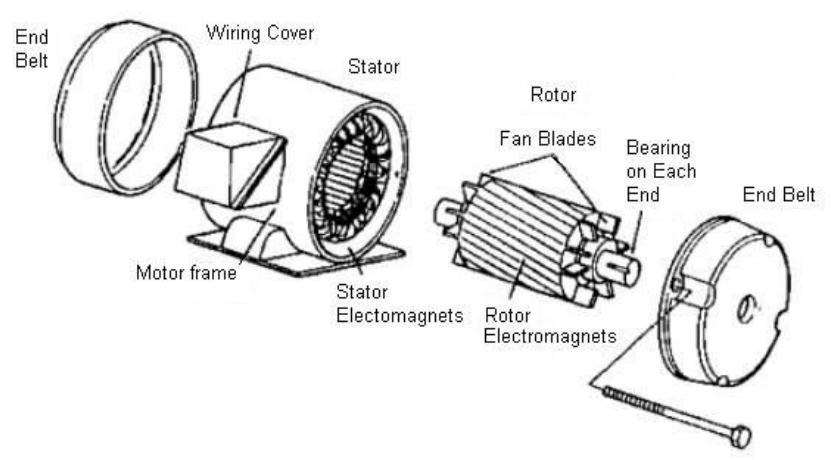

Gambar 1. Konstruksi Motor Induksi 1 Phasa [9]

\section{Daya Listrik}

Daya listrik atau dalam bahasa Inggris disebut dengan electrical power adalah jumlah energi yang diserap atau dihasilkan dalam sebuah sirkuit/rangkaian. Sumber energi seperti tegangan listrik akan menghasilkan daya listrik sedangkan beban yang terhubung dengannya akan menyerap daya listrik tersebut. Dengan kata lain, daya listrik adalah tingkat konsumsi energi dalam sebuah sirkuit atau rangkaian listrik[7]. Dengan rumus sebagai berikut[8]:

$$
P=V \times I
$$

Keterangan:

$P=$ Daya listrik dengan satuan watt $(\mathrm{W})$

$V=$ Tegangan listrik dengan satuan volt $(\mathrm{V})$

$I=$ Arus listrik dengan satuan ampere (A)

\section{Energi Listrik}

Energi Listrik diakibatkan oleh muatan listrik yang bergerak, yang disebut arus listrik (I). Energi listrik banyak dimanfaatkan untuk kebutuhan sehari-hari seperti menyalakan lampu, mengisi daya baterai handphone, menghidupkan komputer, dan lain sebagainya. Energi listrik yang sampai pada rumah anda mengalami proses panjang. Sebagian besar, produksi listrik di Indonesia dilakukan oleh Perusahaan Listrik Negara (PLN)[7]. Dengan rumus sebagai berikut[8]:

$$
W=P \times t
$$

Keterangan:

$W=$ Energi listrik $(\mathrm{Wh})$

$t=$ Waktu (h)

\section{Sensor Arus ACS712}

Pengukuran arus biasanya membutuhkan sebuah resistor shunt yaitu resistor yang dihubungkan secara seri pada beban dan mengubah aliran arus menjadi tegangan. Tegangan tersebut dialirkan ke current transformer terlebih dahulu sebelum masuk ke rangkaian pengkondisi signal. Teknologi hall effect yang diterapkan oleh Allegro menggantikan fungsi resistor shunt dan current transformer menjadi sebuah sensor dengan ukuran yang relatif jauh lebih kecil. Aliran arus listrik yang mengakibatkan medan magnet yang menginduksi bagian dynamic offset cancellation dari ACS712[7]. Gambar 3 menunjukkan bentuk fisik dari sensor arus ACS712

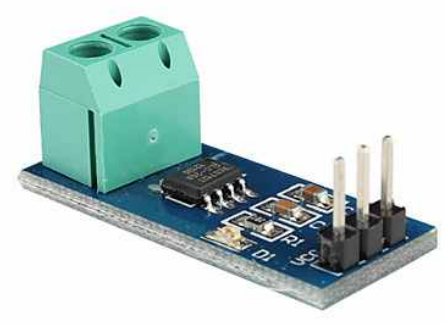

Gambar 2. Sensor Arus ACS712 [9]

Rumus tegangan pada pin out sensor adalah sebagai berikut:

$$
V_{\text {out }}=2,5 \pm(0,185 \times I) .
$$

Keterangan:

$V_{\text {out }}=$ Tegangan listrik pada pin out dalam satuan volt $(\mathrm{V})$

$I=$ Arus yang terdeteksi dalam satuan (A) 


\section{Modul Relay}

Relay adalah komponen elektronik yang digerakkan oleh arus listrik. Ketika batang besi (coil) dialiri arus listrik, tuas akan tertarik karena adanya gaya magnet yang terjadi pada coil sehingga kontak saklar akan menutup. Pada saat arus dihentikan, gaya magnet akan hilang, tuas akan kembali ke posisi semula dan kontak saklar kembali terbuka[7]. Konfigurasi relay ada dua jenis, yaitu:

1. Normally Open (NO), apabila kontak-kontak tertutup saat relay dicatu.

2. Normally Closed (NC), apabila kontak-kontak terbuka saat relay dicatu.

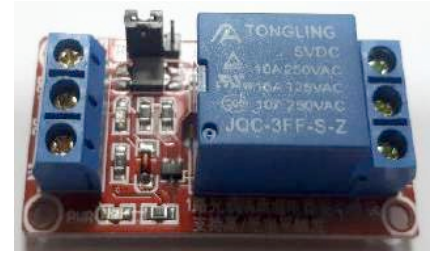

Gambar 3. Modul Relay[11]

\section{Wemos D1}

Wemos merupakan salah satu module board yang dapat berfungsi dengan arduino, khususnya untuk proyek yang mengusung konsep IOT. Wemos dapat bekerja sendiri tanpa perlu dihubungkan dengan mikrokontroler. Wemos dapat bekerja sendiri karena didalammnya sudah terdapat CPU yang dapat memprogram melalui serial port atau via OTA serta transfer program secara wireless[12]. Wemos memiliki 2 buah chipset yang digunakan sebagai otak kerja yaitu chipset ESP8266 dan chipset CH340. Gambar 4 menunjukkan bentuk fisik dari Wemos D1.

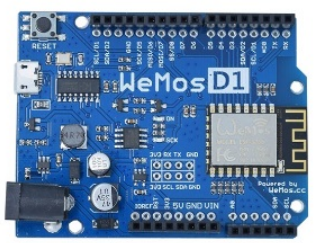

Gambar 4. Wemos D1[13]

\section{Perhitungan Tarif Listrik}

Hal yang harus diperhatikan dalam menghitung tarif listrik yang digunakan adalah TTL(Tarif Tenaga Listrik). Sebagai gambaran, berikut informasi TTL Agustus 2019 untuk kebutuh rumah tangga[7]:

1. Pelanggan listrik R1 450 VA biaya TTL sebesar Rp415,00.

2. Pelanggan listrik R1M 900 VA biaya TTL sebesar Rp605,00.

3. Pelanggan listrik R1 900 VA biaya TTL sebesar Rp1.352,00.

4. Pelanggan listrik R1 1300VA biaya TTL sebesar Rp1.467,28.

5. Pelanggan listrik R1 2200VA biaya TTL sebesar Rp1.467,28.

6. Pelanggan listrik R2 2200 VA s.d. 5500VA biaya TTL sebesar Rp1.467,28.

7. Pelanggan listrik R3 5500 VA s.d. 6600VA biaya TTL sebesar Rp1.467,28.

Setelah mengetahui nilai TTL maka dapat dilanjutkan dengan menggunakan perhitungan sebagai berikut:

$$
\text { Tarif Listrik }=(W \div 1000) \times T T L .
$$

Keterangan:

Tarif Listrik $=$ kisaran biaya yang harus dibayar dalam satuan rupiah (Rp)

$T T L=$ Tarif Tenaga Listrik

Pembagian nilai $W$ dengan 1000 bertujuan untuk mengubah satuan yang awalnya Wh (watt hour) menjadi kWh (kilowatt hour).

\section{METODE PENELITIAN}

\section{Rancangan Umum Sistem}

Berikut rancangan umum sistem dari alat yang dibuat:

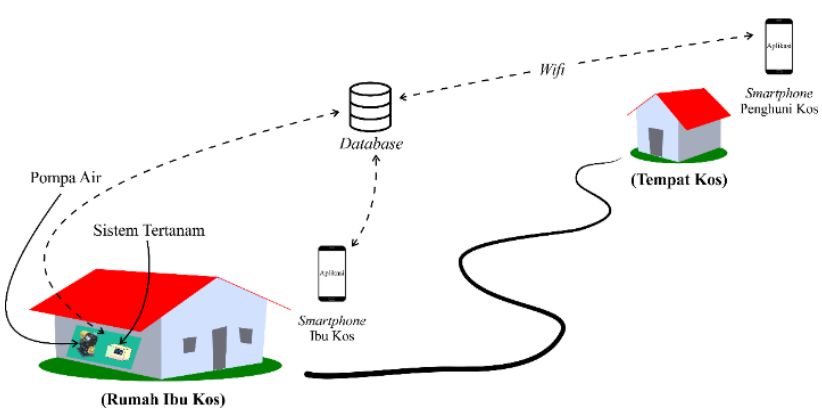

Gambar 5. Rancangan Umum Sistem

Rancangan umum sistem memuat desain arsitektur sistem yang menggambarkan overview sistem yang dibuat. Komponen yang dibutuhkan dalam sistem ini, yaitu pompa air, smartphone, database, dan sistem tertanam yang terdiri dari Wemos D1, sensor arus, dan modul relay.

\section{Rancangan Perangkat Keras}

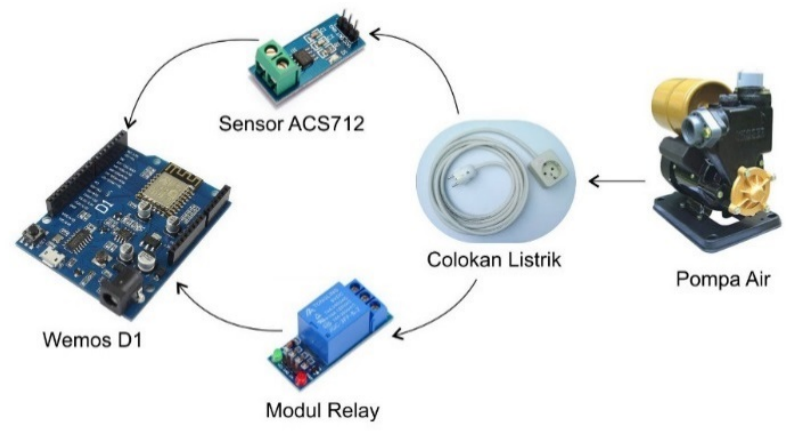

Gambar 6. Rancangan Perangkat Keras

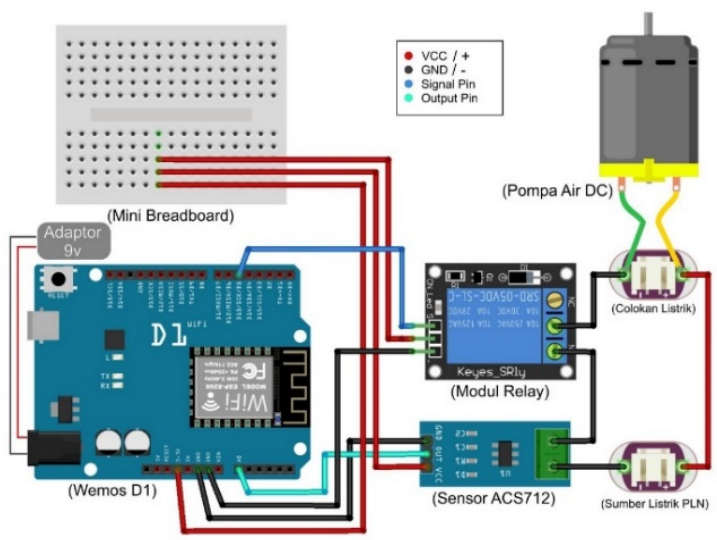

Gambar 7. Rancangan Rangkaian Kelistrikan Sistem 
Berdasarkan perancangan perangkat keras, kegunaan dari masingmasing komponen adalah:

1. Wemos D1 digunakan sebagai mikrokontroler atau pengontrol utama dari sistem yang nantinya akan mengolah masukan yang telah dibaca oleh sensor dan melakukan aksi sesuai program. Modul wifi yang telah tertanam di dalamnya akan digunakan untuk media komunikasi dengan website dan database.

2. Sensor ACS712 digunakan untuk mendeteksi arus yang mengalir pada colokan dan mengirim nilainya ke mikrokontroler. Tujuan selanjutnya yaitu untuk mendeteksi apakah pompa air sudah tersambung ke colokan atau belum dengan indikator penentu, yaitu ada atau tidaknya arus yang mengalir pada colokan, jika ada maka pompa air telah tersambung namun jika tidak maka pompa air belum tersambung.

3. Modul Relay digunakan untuk memutus atau menghubungkan arus listrik pada colokan.

4. Colokan listrik digunakan sebagai tempat mencolokkan pompa air.

\section{Rancangan Proses}
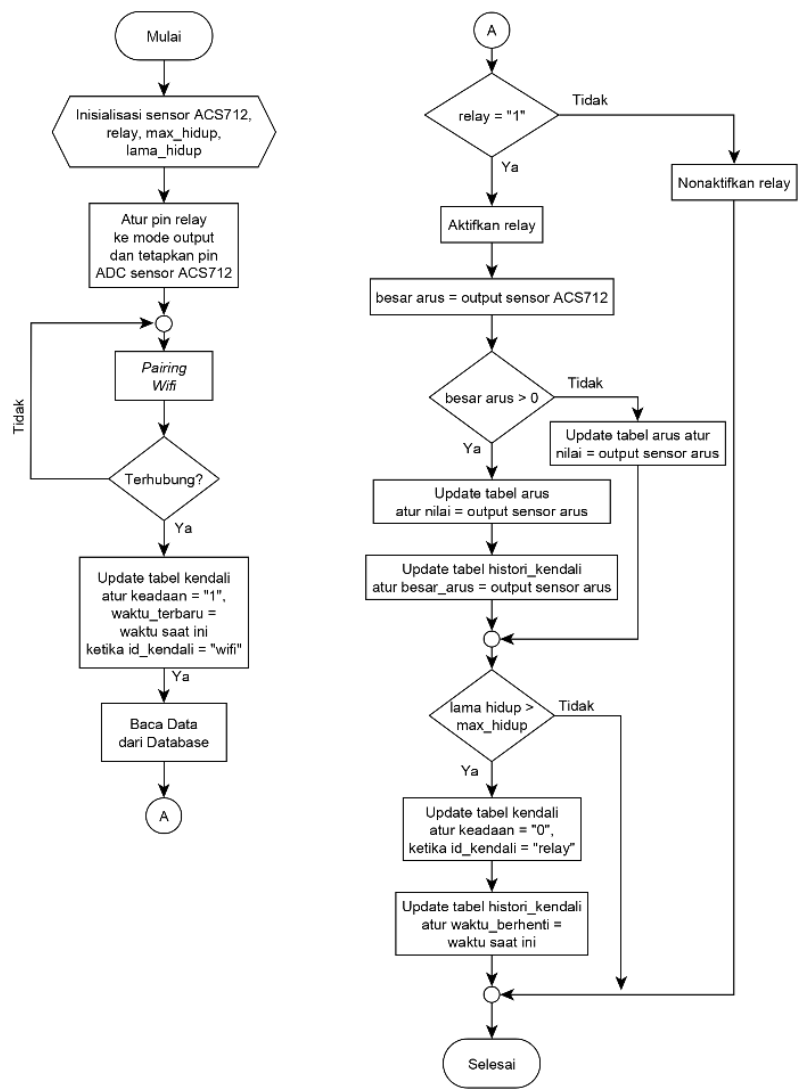

Gambar 8. Flowchart Alur Sistem

Flowchart pada Gambar 8 merupakan proses yang dilakukan pada sistem tertanam. Pada tahap awal, dilakukan inisialisasi variabel yang dibutuhkan, serta dilakukan pengaturan pin relay ke mode output dan menetapkan pin ADC yang akan digunakan untuk sensor ACS 712. Selanjutnya sistem melakukan pairing wifi, jika sudah terhubung, sistem akan melakukan update data wifi beserta waktu terbaru pada database, lalu setelah itu akan membaca data yang diperlukan dari database. Jika data relay pada database bukan bernilai "1", maka relay akan dinonaktifkan, namun jika data relay bernilai "1", maka relay akan diaktikan dan lanjut ke proses berikutnya. Setelah relay diaktifkan, proses berikutnya adalah melakukan pengecekan arus. Jika arus bernilai tidak besar dari 0 , maka akan dilakukan update terhadap nilai arus pada database menjadi 0 , namun jika arus bernilai besar dari 0 , maka akan dilakukan update terhadap nilai arus dan besar arus. Nilai arus digunakan sebagai indikator penentu apakah ada arus yang melalui sistem atau tidak, sedangkan besar arus digunakan untuk tabel histori kendali. Setelah melakukan pengecekan arus, proses selannjutnya adalah melakukan pengecekan lama waktu hidup apakah telah melewati batas atau belum. Jika sudah melewati batas maka akan dilakukan update nilai relay menjadi 0 dan waktu berhenti pada tabel histori kendali diisi dengan waktu saat ini.

\section{Rancangan Interface Aplikasi}

Perancangan interface aplikasi dapat dilihat pada gambar di bawah.

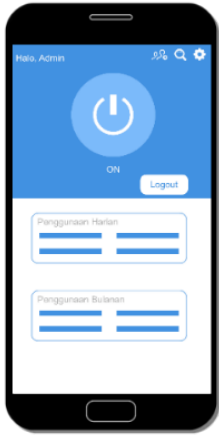

(a)

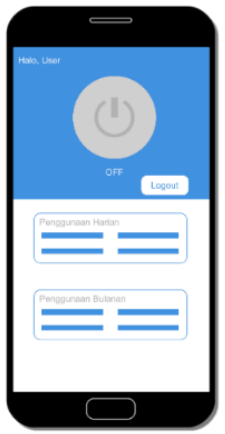

(b)
Gambar 9. Rancangan Halaman (a) Pompa ON (b) Pompa OFF

\section{HASIL DAN PEMBAHASAN}

\section{Implementasi}

\section{Implementasi Perangkat Keras}

Untuk membangun sistem kendali dan monitoring pada pompa air ini, perangkat keras yang digunakan berupa Wemos D1, sensor ACS712, modul relay 1 channel, dan colokan listrik.

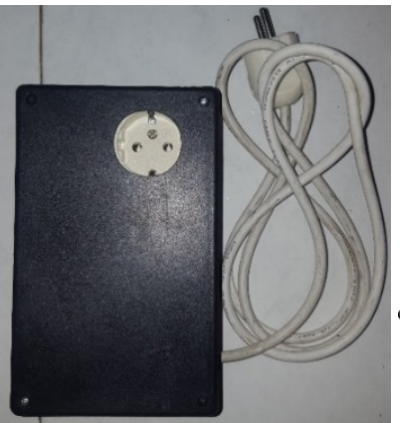

(a)

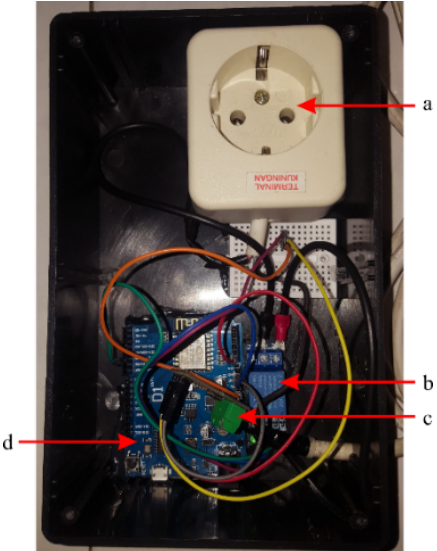

(b)
Gambar 10. Implementasi Perangkat Keras (a) Tampak Luar (b) Tampak Dalam

Keterangan gambar:

a. Colokan, digunakan untuk tempat mencolokkan pompa air. 
b. Modul relay, digunakan untuk menghubungkan/ memutuskan arus pada sistem yang nantinya akan mempengaruhi keadaan dari pompa air yaitu hidup/mati.

c. Sensor arus, digunakan untuk mendeteksi arus yang mengalir pada sistem dan mengecek apakah pompa air sudah terpasang pada alat atau belum, jika arus sama dengan 0 berarti pompa air belum terhubung ke alat, namun jika arus besar dari 0 berarti pompa air sudah terhubung ke alat.

d. Wemos D1, digunakan sebagai mikrokontroler yang memproses seluruh kerja dari sistem. Modul ESP8266 yang merupakan bawaan dari Wemos D1, digunakan sebagai media komunikasi antara sistem tertanam dengan database dan aplikasi mobile yang dibuat.

\section{Implementasi Perangkat Lunak}

Untuk implementasi aplikasi ini terdiri dari beberapa halaman inti yaitu halaman depan user, halaman depan admin, halaman halaman monitoring, dan halaman pengaturan.

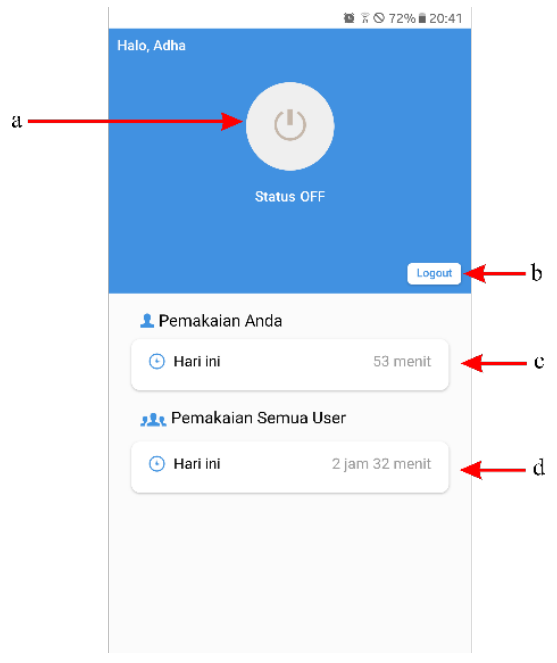

Gambar 11. Halaman User

Keterangan gambar:

a. Merupakan tombol yang digunakan untuk menghidupkan/mematikan pompa air. Tombol ini bersifat toggle yaitu jika ditekan dalam kondisi pompa air mati akan membuat pompa air hidup, sebaliknya jika ditekan dalam kondisi pompa air hidup akan membuat pompa air mati.

b. Tombol logout, digunakan untuk keluar dari status user, sehingga aplikasi akan mengarah ke halaman login. Setelah logout, user harus login kembali agar dapat menggunakan fitur dari aplikasi.

c. Pemakaian pompa air pada hari ini oleh akun yang sedang login.

d. Pemakaian pompa air oleh keseluruhan user dan admin pada hari ini.

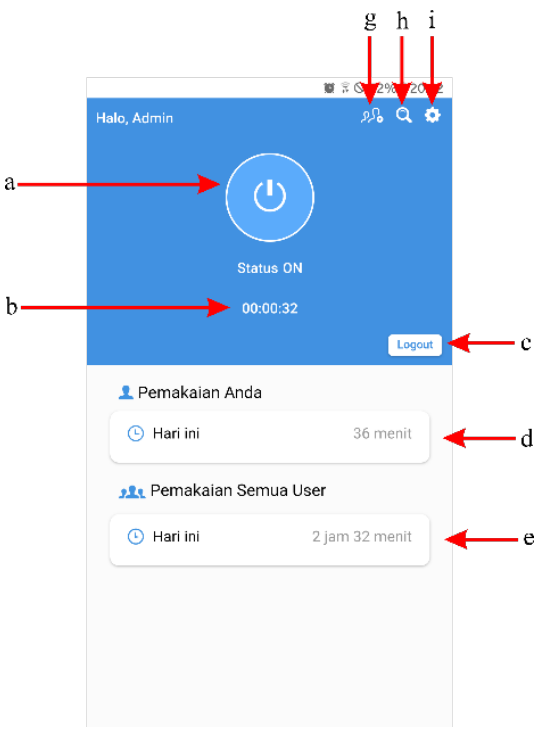

Gambar 12. Halaman Admin

Keterangan gambar:

a. Merupakan tombol yang digunakan untuk menghidupkan/mematikan pompa air. Tombol ini bersifat toggle yaitu jika ditekan dalam kondisi pompa air mati akan membuat pompa air hidup, sebaliknya jika ditekan dalam kondisi pompa air hidup akan membuat pompa air mati.

b. Menandakan lama waktu hidup pompa air saat itu.

c. Tombol logout, digunakan untuk keluar dari status admin, sehingga aplikasi akan mengarah ke halaman login. Setelah logout, admin harus login kembali agar dapat menggunakan fitur dari aplikasi.

d. Pemakaian pompa air pada hari ini oleh akun admin yang sedang login.

e. Pemakaian pompa air oleh keseluruhan user dan admin pada hari ini.

f. Menu yang ketika diklik akan mengarah ke halaman konfirmasi akun user.

g. Menu yang ketika diklik akan mengarah ke halaman monitoring.

h. Menu yang ketika diklik akan mengarah ke halaman pengaturan.

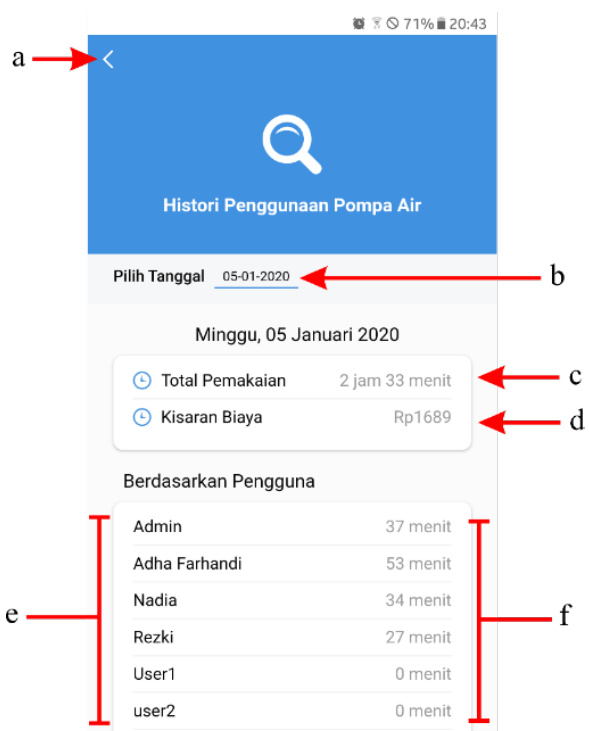

Gambar 13. Halaman Monitoring 
Keterangan gambar:

a. Tombol back, untuk mengarahkan kembali ke halaman utama admin.

b. Field tanggal, diisi untuk melihat data pemakaian pompa air pada tanggal tertentu.

c. Total lama pemakaian pompa air pada tanggal yang telah dipilih.

d. Kisaran biaya pemakaian pompa air pada tanggal yang telah dipilih.

e. Nama-nama pengguna yang menggunakan pompa air.

f. Lama tiap-tiap pengguna dalam menggunakan pompa air pada tanggal yang telah dipilih.

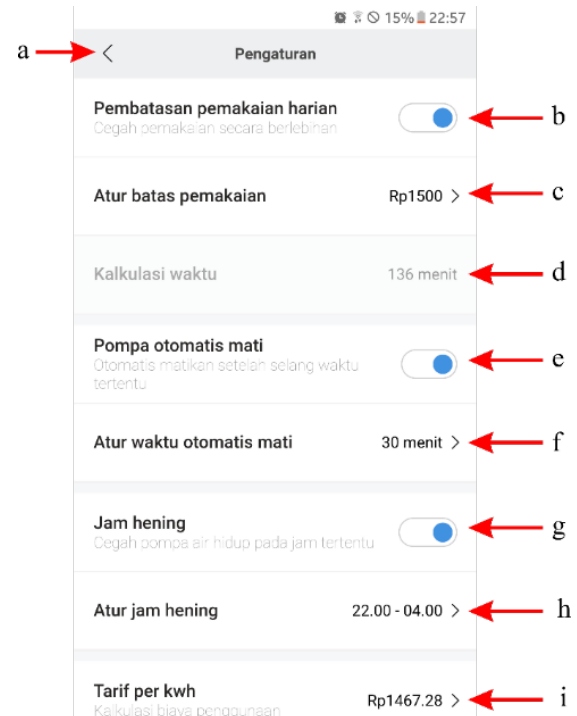

Gambar 14. Halaman Pengaturan

Keterangan gambar:

a. Tombol back, untuk mengarahkan kembali ke halaman utama admin.

b. Tombol untuk mengaktifkan/menonaktifkan mode pembatasan pemakaian harian berdasarkan nominal rupiah.

c. Menu untuk mengatur batas pemakaian harian.

d. Hasil kalkulasi batas pemakaian harian dari nominal rupiah dikonversi ke satuan menit.

e. Tombol untuk mengaktifkan/menonaktifkan mode pompa otomatis mati.

f. Menu untuk mengatur selang waktu untuk pompa air mati otomatis.

g. Tombol untuk mengaktifkan/menonaktifkan mode silent mode.

h. Menu untuk mengatur jadwal silent mode.

i. Menu untuk mengatur tarif per kWh pemakaian listrik.

\section{Pengujian dan Analisa}

\section{Pengujian Sensor Arus ACS712}

Tabel 1. Pengujian Sensor Arus

\begin{tabular}{|c|c|c|c|c|c|}
\hline \multirow{2}{*}{ No. } & Alat & \multicolumn{2}{|c|}{ Bacaan Arus (A) } & Selisih & Error \\
\cline { 3 - 4 } & Multimeter & Sensor & $(\mathrm{A})$ & $(\%)$ \\
\hline 1 & $\begin{array}{c}\text { Pompa Air } \\
\text { Grundfos } \\
\text { GT-H-18V }\end{array}$ & 6.04 & 5.46 & 0.62 & 10.26 \\
\hline \multirow{2}{*}{2} & $\begin{array}{c}\text { Pompa Air } \\
\text { Panasonic } \\
\text { GA-125JBE }\end{array}$ & 0.79 & 0.90 & 0.11 & 13.92 \\
\hline
\end{tabular}

\begin{tabular}{|c|c|c|c|c|c|}
\hline 3 & $\begin{array}{c}\text { Pompa Air } \\
\text { Sanyo P- } \\
\text { WH137C }\end{array}$ & 0.79 & 0.92 & 0.13 & 16.45 \\
\hline 4 & $\begin{array}{c}\text { Pompa Air } \\
\text { Firman }\end{array}$ & 0.92 & 1.05 & 0.13 & 14.13 \\
\hline 5 & $\begin{array}{c}\text { Pompa Air } \\
\text { National }\end{array}$ & 1.12 & 1.27 & 0.15 & 13.39 \\
\hline \multicolumn{4}{|c|}{ Rata-rata error (\%) } & 13.63 \\
\hline
\end{tabular}

Berdasarkan hasil pengujian yang dilakukan, dapat disimpulkan bahwa persentase error rata-rata yang didapatkan dengan membandingkan hasil pengukuran sensor arus ACS712 dengan multimeter adalah sebesar $13.63 \%$.

\section{Pengujian Sistem Secara Keseluruhan}

Pengujian sistem secara keseluruhan dilakukan pada Kos XYZ. Pada kos tersebut terdapat sebuah pompa air yang digunakan oleh pemilik kos dan penyewa kos secara bersama-sama. Pompa air terletak di rumah pemilik kos dan jarak dari tempat penyewa kos ke tempat pemilik kos sekitar 30 meter. Pengujian yang dilakukan meliputi pengujian halaman monitoring, pengujian lama waktu respon, dan pengujian menghidupkan pompa air dalam berbagai kondisi seperti saat pemakaian harian telah melebihi batas, dan pemakaian pada saat rentang waktu silent mode. Pengujian dilakukan dengan menggunakan koneksi internet dari provider Telkomsel pada jaringan $4 \mathrm{G}$.

Pengujian dilakukan dengan mengubah tahun serta memilih bulan pada bagian atas halaman monitoring. Skenario pengujian dibagi menjadi dua kategori yaitu untuk tanggal yang memiliki data pemakaian pompa air dan untuk tanggal yang tidak memiliki data pemakaian pompa air.

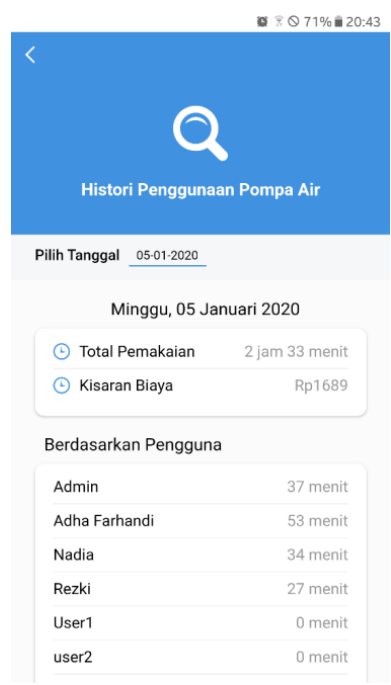

(a)

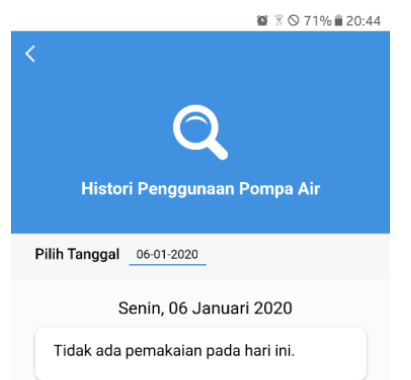

Gambar 15. Pengujian Halaman Monitoring (a) Ada data (b)Tidak ada data

Dari hasil pengujian dapat dilihat bahwa, aplikasi menampilkan data pemakaian ketika pada tanggal tersebut terdapat pemakaian pompa air, sedangkan jika tidak ada pemakaian pompa air maka aplikasi akan memberikan pesan bahwa tidak ada pemakaian pada hari tersebut. Pengujian dilakukan tanggal 5 Januari 2020, pada hari itu terjadi pemakaian pompa air selama 2 jam 33 menit dengan kisaran biaya pemakaian yaitu 1689 rupiah, sedangkan pada tanggal 6 Januari, yang berarti besok harinya, belum terdapat data 
pemakaian pompa air, sehingga aplikasi menampilkan pesan tidak ada pemakaian pada hari tersebut.

Pengujian lama waktu respon dilakukan dengan cara menghidupkan pompa air melalui aplikasi yang telah dibuat, dimana semua alat telah terkoneksi dengan wifi dan pompa air telah terhubung ke alat. Tujuannya adalah untuk mengetahui berapa lama waktu yang dibutuhkan mulai dari tombol pada smartphone ditekan sampai pompa air dapat hidup.

Tabel 2. Pengujian Lama Waktu Respon

\begin{tabular}{|c|c|c|c|}
\hline $\begin{array}{c}\text { Percobaan } \\
\text { ke- }\end{array}$ & Hasil & $\begin{array}{c}\text { Kesesuaian } \\
\text { dengan } \\
\text { hasil }\end{array}$ & $\begin{array}{l}\text { Waktu } \\
\text { Respon } \\
\text { (detik) }\end{array}$ \\
\hline 1 & Hidup & Sesuai & 1 \\
\hline 2 & Hidup & Sesuai & 2 \\
\hline 3 & Hidup & Sesuai & 1 \\
\hline 4 & Hidup & Sesuai & 1 \\
\hline 5 & Hidup & Sesuai & 4 \\
\hline 6 & Hidup & Sesuai & 5 \\
\hline 7 & Tidak Hidup & Tidak & - \\
\hline 8 & Hidup & Sesuai & 1 \\
\hline 9 & Hidup & Sesuai & 2 \\
\hline 10 & Hidup & Sesuai & 1 \\
\hline \multicolumn{3}{|c|}{ Rata-rata Waktu Respon (detik) } & 2 \\
\hline
\end{tabular}

Berdasarkan pengujian yang dilakukan sistem berhasil menghidupkan pompa air sebanyak 9 kali dari 10 kali percobaan dengan rata-rata waktu respon untuk menghidupkan yaitu 2 detik. Terjadi satu kali kegagalan saat menghidupkan pompa dikarenakan koneksi internet yang sedang tidak stabil (tidak ada koneksi) sehingga data yang seharusnya terkirim menjadi tidak tidak terkirim yang mengakibatkan kegagalan sistem dalam menghidupkan pompa air.

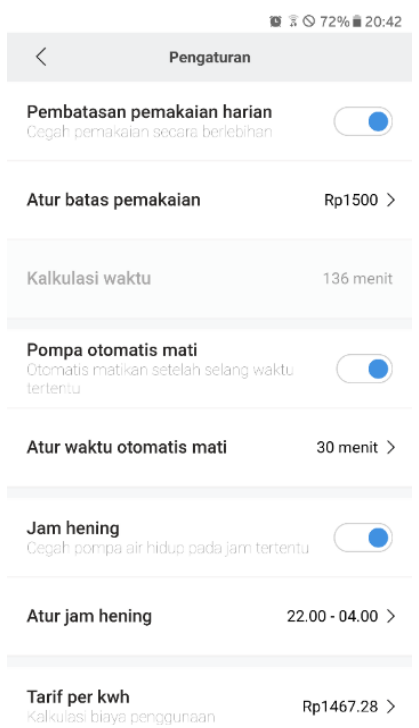

Gambar 16. Pengaturan Batas Harian

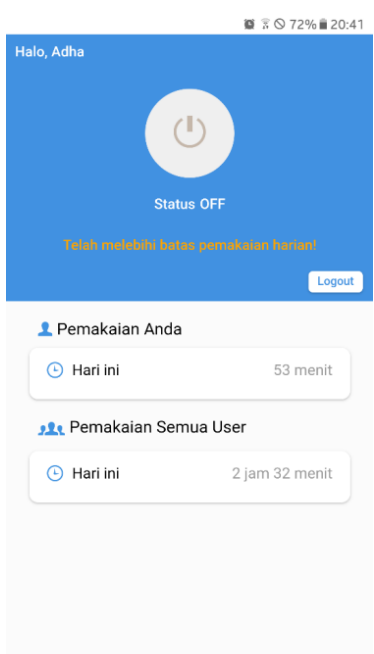

(a)

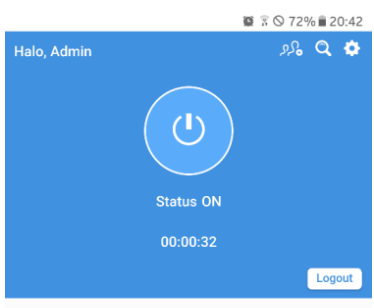

2 Pemakaian Anda

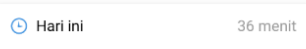

2le Pemakaian Semua User

(1) Hari ini (b)
Gambar 17. Pengujian Batas Harian (a) User (b) Admin

Pengujian melebihi batas pemakaian dilakukan saat batas pemakaian harian telah terpenuhi, serta kondisi pengaturan dari mode pembatasan harian dalam keadaan aktif. Saat pompa air tetap ingin dihidupkan oleh user, sesuai dengan perancangan alat, sistem akan menolak untuk hidup karena telah melewati batas pemakaian harian.

Total pemakaian pompa air yaitu 2 jam 32 menit dan batas pemakaian yaitu 2 jam 12 menit (136 menit) yang artinya pemakaian pompa air telah melebihi batas harian. Ketika user menghidupkan pompa air sistem berhasil menolak, sedangkan ketika admin menghidupkan pompa air sistem tidak menolak, hal ini terjadi karena pembatasan hanya berlaku pada user, namun tidak pada admin. Berdasarkan pengujian yang dilakukan, sistem telah mampu bekerja sesuai dengan sistem yang dirancang pada bagian pembatasan harian pemakaian pompa air.

Pengujian dilakukan saat memasuki yang waktu telah diatur oleh admin, serta kondisi pengaturan dari silent mode dalam keadaan aktif. Saat pompa air tetap ingin dihidupkan oleh user, sesuai dengan perancangan alat, sistem akan menolak untuk hidup karena waktu saat ini adalah silent hours, yang mana tidak boleh menghidupkan pompa air.

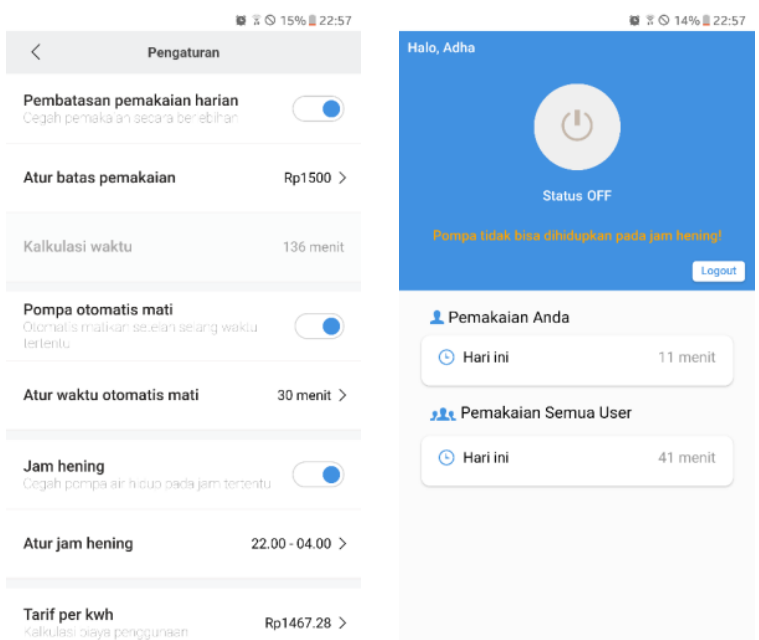

(a)

(b)

Gambar 18. Pengujian Silent Mode (a) Pengaturan (b) User 


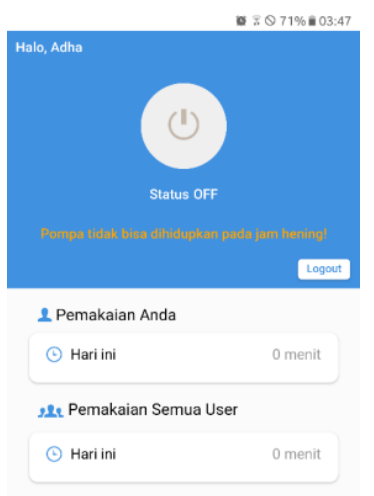

(a)

(b)

Gambar 19. Pengujian Silent Mode (a) User (b) Admin

Silent hours diatur pada sistem dari jam 22.00 - 04.00. Pengujian menghidupkan pompa air dilakukan pada jam 22.57 dan 03.47, hasilnya yaitu aplikasi menolak untuk menghidupkan pompa air, karena masih dalam rentang silent hours. Sedangkan ketika admin menghidupkan pompa air pada jam 03.49 sistem tidak menolak proses tersebut, hal ini terjadi karena pembatasan silent hours tidak berlaku untuk admin. Berdasarkan pengujian yang telah dilakukan, sistem telah mampu bekerja sesuai sistem yang dirancang pada bagian silent mode.

\section{KESIMPULAN}

Berdasarkan perancangan, pengamatan, dan pengujian yang telah dilakukan maka dapat diambil kesimpulan sebagai berikut:

1. Sistem dapat menghidupkan/mematikan pompa air menggunakan aplikasi mobile yang bisa diakses melalui smartphone.

2. Sistem dapat memperlihatkan data pemakaian harian, serta kisaran biaya yang harus dibayarkan untuk penggunaan pompa air. Sistem juga dapat secara lebih spesifik menunjukan berapa lama pemakaian pompa air berdasarkan masingmasing user. Kisaran biaya memiliki nilai eror $13.63 \%$ dikarenakan hasil dari pembacaan sensor arus merupakan salah satu variabel yang digunakan dalam perhitungan kisaran biaya.

\section{DAFTAR PUSTAKA}

[1] Hersyah, M., Dinata, D., \& Firdaus. 2017. Identifikasi Rancang Bangun Alat Ukur dan Sistem Kendali Kadar Total Dissolved Solid (Tds) pada Air Berbasis Mikrokontroler. JITCE (Journal of Information Technology and Computer Engineering). 01(01): 26-34.

[2] Bahrin. 2017. Sistem Kontrol Penerangan Menggunakan Arduino Uno pada Universitas Ichsan Gorontalo. ILKOM Jurnal Ilmiah. 09(03): 282-289.

[3] Zulpa, Arieman. 2015. Prototype Monitoring Pengukuran Beban dan Biaya Arus Listrik dengan Mikrokontroler Arduino pada Pelanggan Pascabayar Berbasis Web. Jakarta: Universitas Islam Negeri Syarif Hidayatullah.

[4] Tiffani, A., Putra, D., \& Erlina, T. 2017. Sistem Monitoring Suhu, Kelembaban, dan Gas Amonia pada Kandang Sapi Perah Berbasis Teknologi Internet of Things (IOT). JITCE (Journal of Information Technology and Computer Engineering). 01(01): 1-7.

[5] Ikponmwosa, O. 2010. "Development of an Electric Water Pump Controller and Level Indicator". Journal of International Journal of Engineering and Applied Sciences. Vol.3, pp.18-21.

[6] Chapman, S. 2005. Electric Machinery Fundamentals 4th Edition. New York: The McGraw,Hill Companies. Inc.

[7] Khumairoh, Isnaini \& Rijanto, Tri. 2019. Sistem kWh Meter Prabayar Menggunakan SMS Gateway. Jurnal Teknik Elektro. 08(02): 383-390.

[8] Boylestad. 2003. Introductory Circuit Analysis, Tenth edition. Prentice Hall Pearson Education International.

[9] Nusa, Temy, dkk. 2015. Sistem Monitoring Konsumsi Energi Listrik Secara Real Time Berbasis Mikrokontroler. Manado: UNSRAT.

[10] Shafiudin, Sofyan. 2017. Sistem Monitoring Dan Pengontrolan Temperatur Pada Inkubator Penetas Telur Berbasis PID. Surabaya: UNESA.

[11] Pakpahan, Sahat Martua Parulian. 2018. Rancang Bangun Amf-Ats Berbasis Sim800l Dengan Fungsi Monitoring Status Switching Pada Genset. Surabaya: Universitas Negeri Surabaya.

[12] Limantara, A. D., Candra, A. I., \& Mudjanarko, S. W. 2017. Manajemen Data Lalu Lintas Kendaraan Berbasis Sistem Internet Cerdas. Jakarta: Universitas Muhammadiyah Jakarta.

[13] Kodali, R. K., \& Sahu, A. 2016. An IoT Based Weather Information Prototype Using WeMos. 2016 2nd International Conference on Contemporary Computing and Informatics (IC3I). 